\title{
Editorial
}

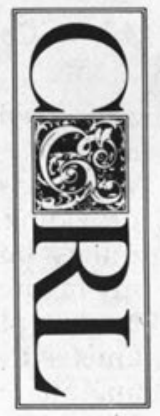

\section{Performance at the Reference Desk}

Reference librarians may answer as many as, if not more than, a hundred questions daily. To accomplish this they use intuition, judgment, and experience within a continuously shifting set of situations. Some reference librarians are marvels to behold as they weave together a web of possibilities, often from a tenuous starting point. They take garbled messages and create sense and understanding so that the user goes away thankful and more enlightened. They give the bibliographical enterprise a coherence that would be impossible without their intervention.

Local surveys and library self-studies of users often conclude that reference librarians have been admirably successful in meeting campus needs. The regard that the public has for libraries may be directly linked to this success.

As a reference librarian at Berkeley, I derived considerable satisfaction from serving at the desk. I helped many users and, in turn, I learned from them. Often I was amazed by what I had constructed for a user's benefit, although I was never a marvel to behold. How many questions did I answer? Certainly less than a billion, although on some days I wanted MacDonald's golden arches on which to record the number of questions answered.

Nevertheless, there was one question that I never answered: how well am I doing? I am somewhat embarrassed about this because it may well represent the most important question that I ever faced. I am certain that I answered most questions correctly. On a percentage basis I easily beat the .351 batting average that gave Tony Gywnn the National League batting championship. If I discount the easy questions that probably accounted for 80 percent of my total, however, I would have to reconsider the effectiveness of my performance. And it is, after all, this smaller percentage that proves my value to society and justifies the support that society accords to our profession.

My discussions with other reference librarians and my review of the literature have led me to conclude that few librarians would be able to answer objectively this same question: how well are you doing? Thomas Childers ['Test of Reference," Library Journal 105:924-28 (April 15, 1980)] and Peter Hernon and Charles McClure ['Referral Services in U.S. Academic Depository Libraries: Findings, Implications and Research Needs, " $R Q$ 22:152-63 (Winter 1982)] have examined the question and conducted studies that found significant error rates. In the Childers study, the staff of one public library incorrectly answered 85 percent of all questions!

In the October 15, 1984, LJ Hotline, there was a report on a Maryland reference survey conducted in twenty-two public library systems. Only 55 percent of all moderately difficult questions were answered correctly: 5.7 percent were answered incorrectly. Problems related to question negotiation accounted for the remainder. Similarly, Childers found that in many situations reference staff failed to probe for a user's underlying need. When I first encountered the Childers study, I was dismayed. However, I was busy dealing with the future, i.e., the next reference question. I was busy with collection development, database searching and committee assignments. There was always too much to do, and I was never forced to answer the question about my "true" level of reference effectiveness.

I have now reached a new phase in my professional development. Some of the questions 
addressed in a perfunctory fashion in the past now seem to be crucial-keys to our progress as a profession. I do not serve on the desk anymore except on a volunteer basis on some weekends. Nevertheless, it seems to me that some questions, such as how effectively am I providing reference service, do not get any easier to answer as time goes by. I may do other things, but some questions linger and remain unanswered. I can accept responsibility for my failure to search deliberately for answers, but I also believe the system in which we operate plays a critical role. The professional model addresses the question of evaluation and feedback. It is one hallmark of the professions, as enumerated by William Goode in his analysis of librarianship as a profession ['The Librarian: From Occupation to Profession?" Library Quarterly 31 (October 1961)]. I have come to the conclusion that, as professionals, we have abdicated a basic responsibility to establish the systematic conditions upon which to evaluate our own performance as reference librarians.

As an editor, I have received few articles that tackle what might be considered the most pressing, perplexing, and important issues in academic librarianship. I have yet to review any articles that deal with the evaluation of reference. I have not seen any articles in the literature that demonstrate why reference librarians and libraries have avoided the detailed evaluation of this function or why they have not developed self-managed but systematic efforts at self-improvement. I can, however, imagine that a parallel exists between the resistance of teaching faculty to classroom evaluation and the de facto resistance of librarians to the evaluation of reference services.

Reference librarians most assuredly learn and continue to develop their skills through a wide variety of methods-workshops, continuing education programs, coursework, and others. Reference departments hold meetings to discuss major reference works, new acquisitions, new databases, problem patrons, and question/answer negotiation. The informal suggestions and advice of colleagues are valuable sources of feedback. Day-to-day experience may be the best vehicle for developing an indirect, almost unconscious sensitivity to how one is performing. However, it is not systematic, it is not formal, and it is subject to an enormous degree of bias. The degree of subjectivity might quite literally overwhelm the accuracy of the interpretation of performance.

It would be interesting to read more studies on this general topic. How do individual perceptions of reference performance match actual performance? What nonverbal behaviors facilitate successful question/answer negotiation? How should we measure reference performance? Are more systematic assessments necessary? What techniques might be used-unobtrusive measures, formal user feedback, consultations with and advice from informed colleagues, or self-managed methods? How effective are the search strategies that reference librarians use? How does the environment in which we work discourage such assessment? Why have reference librarians and other library employees not undertaken such assessment? Are there methods that individual reference librarians might use to assess themselves in order to improve their performance and the number of correct answers they give?

This is a rich area for insightful research. It resembles a frontier that should be crossed, not only by researchers but also by each and every reference librarian. If we are in search of excellence, there is no better place to start. Our status in the "Knowledge Society" may one day depend on the objective knowledge that we have of our own performance and professional expertise.

\section{CHARLES MARTELL}

